Portland State University

PDXScholar

5-13-1974

\title{
The Digital Multifunction Power Measuring System
}

Ralph Warren Shoemaker

Portland State University

Follow this and additional works at: https://pdxscholar.library.pdx.edu/open_access_etds

Part of the Electrical and Computer Engineering Commons Let us know how access to this document benefits you.

\section{Recommended Citation}

Shoemaker, Ralph Warren, "The Digital Multifunction Power Measuring System" (1974). Dissertations and Theses. Paper 2044.

https://doi.org/10.15760/etd.2043

This Thesis is brought to you for free and open access. It has been accepted for inclusion in Dissertations and Theses by an authorized administrator of PDXScholar. Please contact us if we can make this document more accessible: pdxscholar@pdx.edu. 
AN ABSTRACT OF THE THESIS OF Ralph Warren Shoemaker for the Degree of Master of Science in Applied Science presented May 13, 1974.

Title: A Digital Multifunction Power Measuring System.

APPROVED BY MEMBERS OF THE THESIS COMMTTEE:

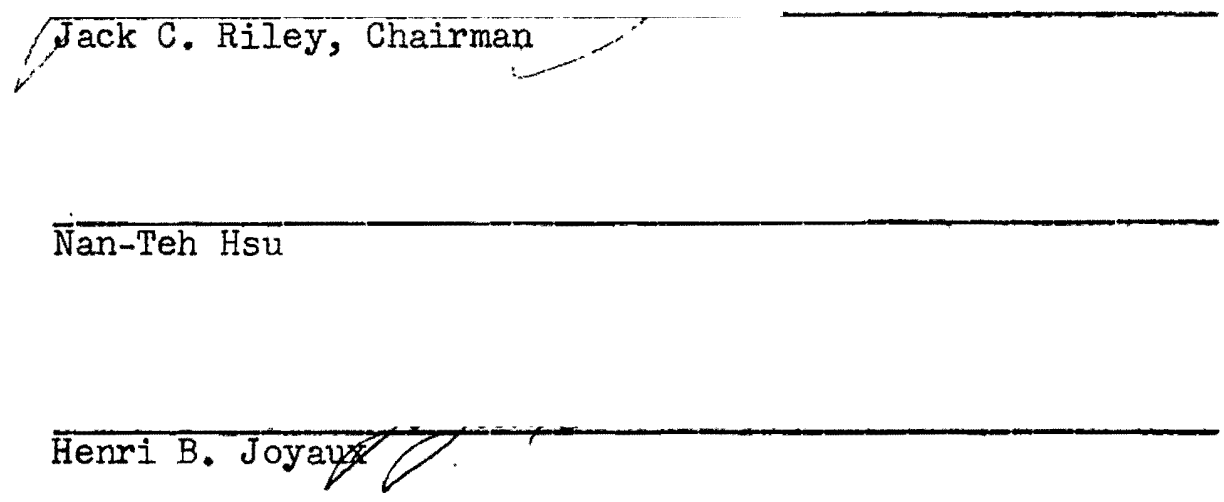

The Digital Multifunction Power Measuring System is the outgrowth of a project involving the design of a prototype precision Digital Watt Transducer for the Bonneville Power Administration (BPA). A prototype Digital Watt Transducer was built and tested since no other device of the desired accuracy was commercially available. Upon partial completion of the project, another Watt Transducer did become available which was essentially identical to our development. Since we could not economically compete with the manufacturer of these Watt Transducers, our project was stopped. Over a period of several months, we thought about other ways to apply the experience gained from the Watt Transducer project, and came upon the idea of designing a precision multifunction power meter to 
help simplify the calibration of Watt and VAR transducers in the Instrumentation and Standards Laboratory, and possibly replace approximately five less accurate analog meters presently used by our Meter-Relay Craftsmen in their field testing. Since no similar meter was available, and since possible revenues lost to inaccurate measurement could justify the development costs of such a meter, we were given authorization to design and build it. This instrument is the Digital Multifunction Power Measuring System which measures the following electrical parameters to approximately plus or minus one-tenth of one percent or better accuracy:

True RMS AC Volts in two ranges.

True RMS AC Amps in six ranges.

Watts in twelve ranges.

VARs in twelve ranges.

Phase Angle between Volts and Amps in all ranges. DC Volts in three ranges.

This instrument has been completed, tested, and calibrated to its design accuracies and is presently being demonstrated within the BPA system to make its availability known to those personnel who might have need for such an instrument. 
THE DIGITAL MULTIFUNCTION POWER MEASURING SYSTEM

$$
\text { by }
$$

RALPH WARREN SHOEMAKER

A thesis submitted in partial fulfillment of the requirements for the degree of

\author{
MASTER OF SCIENCE \\ in \\ APPIIED SCIENCE
}

Portland State University

1974 
TO THE OFFICE OF GRADUATE STUDIES AND RESEARCH:

The members of the Committee approve the thesis of

Ralph Warren Shoemaker presented May 13, 1974.

Jack C. Riley, Chairman

Nan-Teh Hsu

Henri B. Joyaux

APPROVED:

Nan-Teh Hsu, Head, Department of Applied Science and Engineering

Dr. Dafid T. Clark, Dean of Graduate Studies 


\section{TABLE OF CONTENTS}

PACE

ACKNOWLEGEMENTS. . . . . . . . . . . . . . . iii

IIST OF TABLES. . . . . . . . . . . . . . . V V

IIST OF FIGLRES . . . . . . . . . . . . . . vi

INTRODUCTION. .......................... I

THE DIGITAL MULTIFUNCTION POLER MEASURING SYSTEM. . . . . 6

I GENERAL DESCRIPTION. . . . . . . . . . . 6

II DETAIIED DESCRIPTION . . . . . . . . 8

Mathematics of the Measurements. . . . . 10

Operational Description......... 10

True RMS Conversion. . . . . . . . 12

AC Volts Circuit . . . . . . . . . 13

AC Amps Circuit. . . . . . . . . . 14

Watts and VARs Circuit . . . . . . . . 15

Phase Angle Circuit. . . . . . . . . 17

DC Volts Circuit.............. 19

Description of Operation, Logic Circuit. . . . 20

Mathematics of the Logic Circuit . . . . . 21

Construction ................. 24

SUMMARY . . . . . . . . . . . . . . . 30

REFERENCES. . . . . . . . . . . . . . . $3 I$ 


$$
1
$$

\section{LIST OF TABIES}

TABIE

PAGE

I Quantities Measured, Ranges and Accuracies. . . 8

II Logic Designation of Functions and Ranges . . . . 20 


\section{LIST OF FIGURES}

I Digital Watt Transducer Block Diagram . . . . . 2

2 Digital Watt Transducer Waveshapes. . . . . . . 3

3 The Digital Multifunction Power Measuring System. • 5

4 System Block Diagram. . . . . . . . . . . 7

5 AC Volts Circuit Block Diagram. ......... 13

6 AC Arms Circuit Block Diagram .......... 14

7 Watts/VARs Circuit Block Diagram. ......... 15

8 Phase Angle Circuit Block Diagram . . . . . . 17

9 DC Volts Circuit Block Diagram. ......... I9

$10^{\prime}$ Decimal Point Logic Diagram . . . . . . . . 22

11 Switching and Scaling Logic Diagram ........ 23

12 Top View of Instrument Showing Location of Circuit Boards, Switch, and Digital Panel Meter. . . 26

13 AC Volts and Phase Shifter Circuit Board. . . . . . 27

$14 \mathrm{AC}$ Amps and RMS Scazer Circuit Board. . . . . . . 27

15 Multiplier Module and Watts/VARs Range Amplifier Circuit Board. . . . . . . . . . 28

16 RMS Module Circuit Board............ 28

17 Phase Angle Circuit Board . . . . . . . . . 29

18 Switching, Scaling, and Decimal Point Logic Circuit Board. ........ 29 


\section{INTRODUCTION}

I. BACKGROUND BEHIND THE DIGITAL MULTIFUNCTION POWER MEASURING SYSTEM

The need within the Bonneville Power Administration (BPA) for more accurate field measurement of power quantities was determined through consultation among the Head of the Low Frequency Standards Unit and Measurement Systems Staff of the Instrumentation and Standards Laboratory and other Units and Sections within BPA. Since we in the Labs were intimately familiar with the measuring of these quantities (Watts, VARs, Amps, Volts, and Phase Angle), but not very familiar with circumstances requiring these measurements in various substations and remote monitoring stations, we had to elicit a great deal of information from other people within BPA as to their needs and what problems they had encountered. The result was the fact that we were unable to purchase Watt Transducers with accuracy better than approximately one percent, and these decreased in accuracy greatly at low power factors. Since BPA's gross revenues are approximately one hundred forty million dollare per year, an inaccuracy of one percent could result in either undercharges or overcharges to our customers of approximately one hundred forty thousand dollars per year. If we were able to develop a watt transducer with accuracy approaching one-tenth of one percent, this could result in savings of approximately one hundred twenty six thousand dollars per year. This was enough to justify a comprehensive study into the feasibility of building a Watt transducer with one-tenth of one percent accuracy. This study, 
performed within the Labs, was the beginning of an extended project culminating in this thesis.

The first result of this study was a prototype circuit of a Watt transducer including only the electronics necessary to perform the multiplication of sixty Hertz voltages representing Volts and Amps inputs. The input voltage divider and current transformer necessary to make this a complete transducer were not included due to their being relatively mundane and easily included at a later time. The block diagram of the Watt transducer, Figure 1, follows.



Figure 1. Digital Watt Transducer Block Diagram. Circled numbers correspond to waveshapes at that point as shown in Figure 2, following 

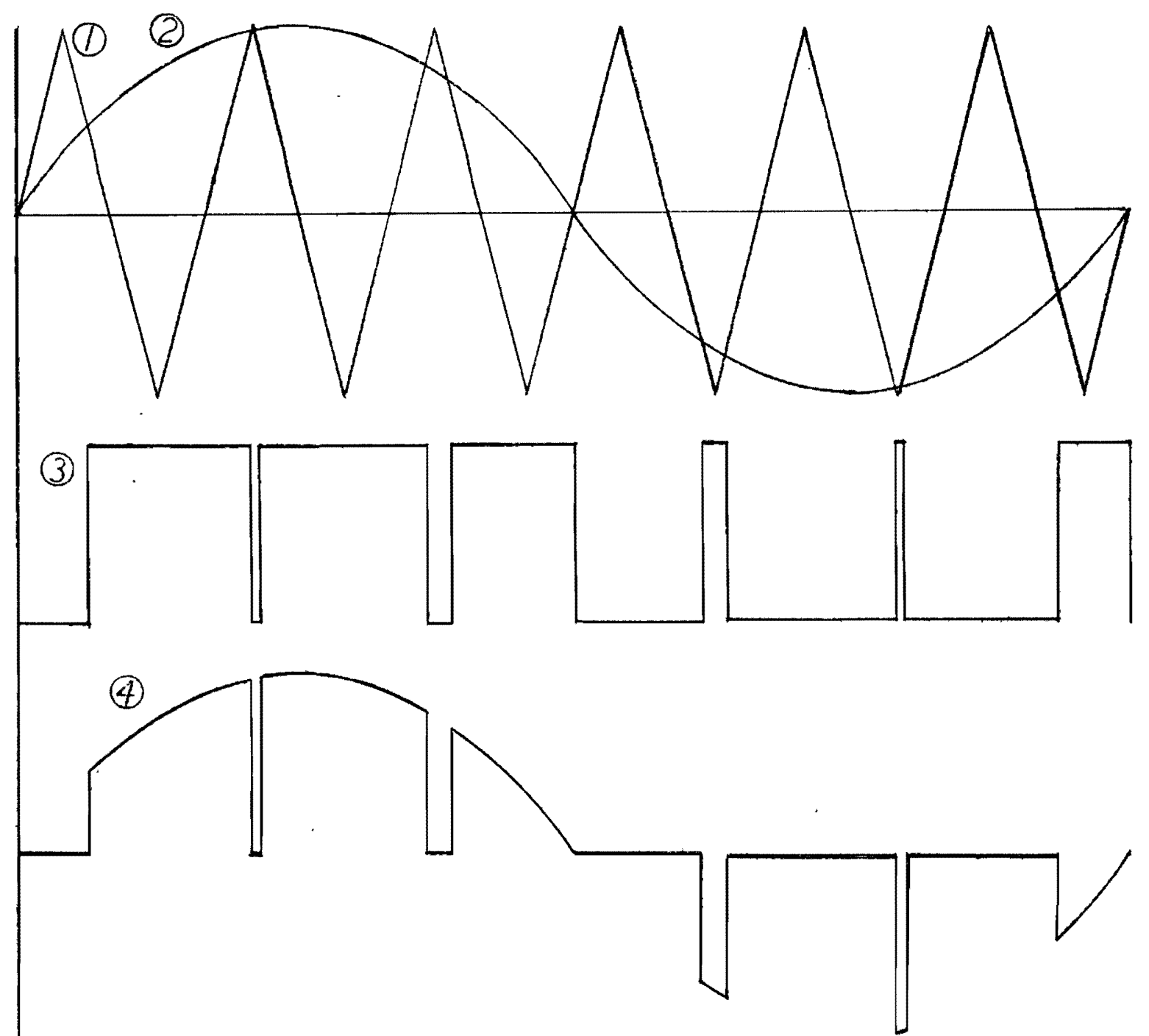

(5)

Ground Reference

Figure 2. Watt Transducer Waveshapes at Point Indicated.

1 Ten kilo Hertz pulse width modulating triangle wave.

2 Sixty Hertz voltage sine wave superimposed over 1 .

3 Width modulated, pulse height modulator control wave.

4 Pulse width modulated current sine wave prior to filtering.

5 Resultant DC voltage output proportional to Watts. 
Upon completion of our Watt transducer prototype, a manufacturer of various types of transducers visited us with a production prototype of a new Watt transducer they were planning to market in the near future. After evaluation and test of their transducer using our Watt-Hour Meter Calibration Console, it was discovered that both they and we had exactly paralleled each others' development and had essentially identical transducers. This resulted in the immediate stoppage of our project due strictly to economics, that is, it was much more economical for us to buy their transducer then to try to produce our own since we are not a manufacturing facility.

With the Watt transducer project stopped, we thought of other practical projects upon which to apply the experience gained on this one. The one upon which we settled was an application of our Wattmeter to a multifunction instrument which could make most or all of the necessary measurements required in routine substation maintenance visits. A meter-relay craftsman needs to measure five and sometimes six quantities on these routine visits to remote and/or unmanned substations, RMS Volts, RMS Amps, Watts, VARs, and Phase Angle. Occasionally he needs to set DC voltages on various types of relays or make other $D C$ measurements raising need for a sixth quantity to be measured. Until the design of the instrument described here, the craftsman needed to carry with him six separate instruments of limited accuracy to measure these electrical parameters. We felt that if we could come up with a single instrument to measure these six parameters accurately, it would supply the cost-effectiveness to justify the cost involved in the design of such an instrument since none was available commercially. This then is the background leading to the design of the Digital Multifunction Power Measuring System, the subject of this thesis. 


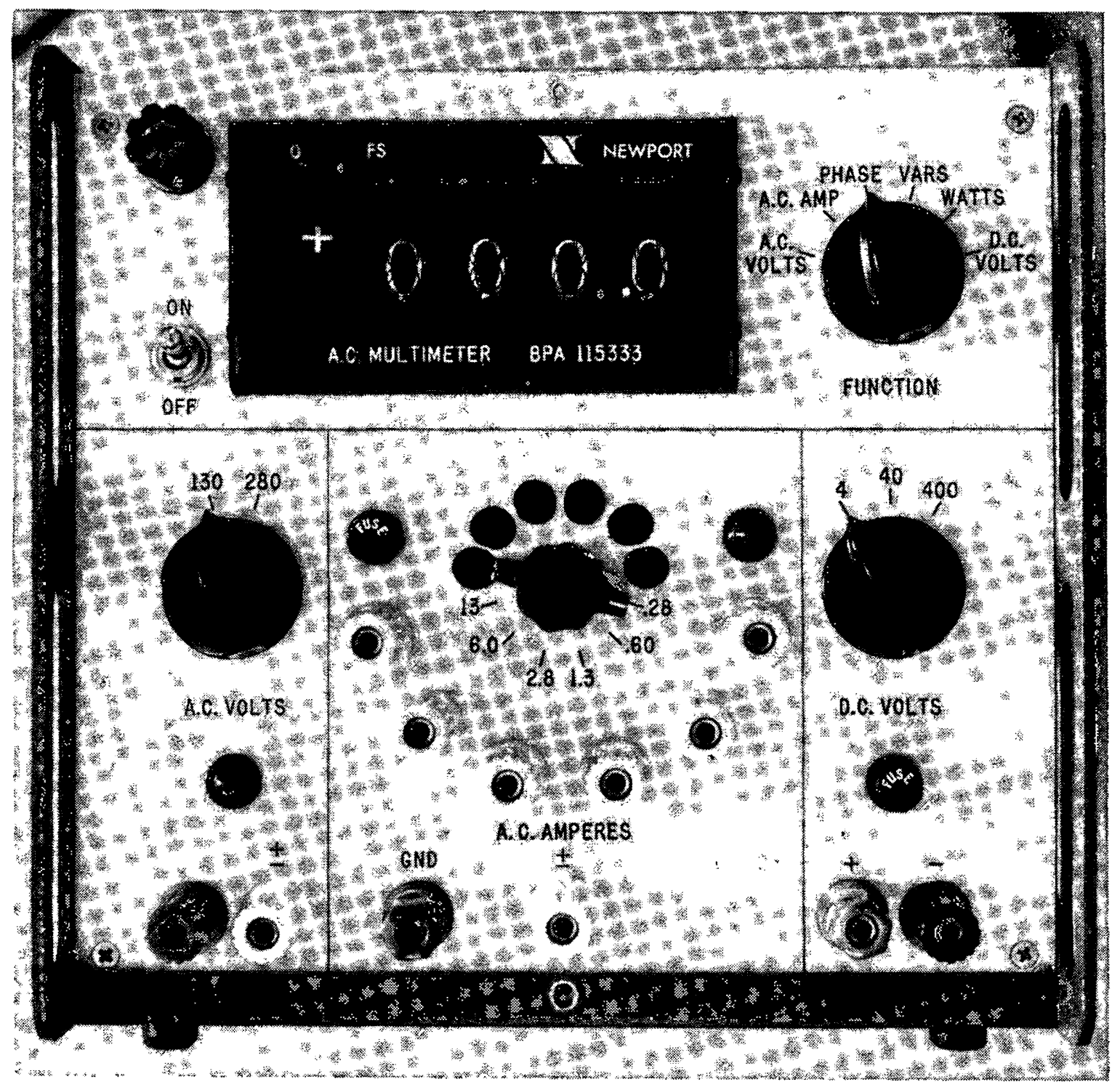

Figure 3. The Digital Multifunction Power Measuring System. 
PHE DIGITAL MULTIFUNCTION POWER MEASURING SYSTEM

The primary purpose of the Digital Multifunction Power Measuring System is to provide a single, portable instrument capable of accurate measurement and display of the six basic electrical power parameters. Simplicity of terminal connection and ease of switching between the practical ranges for each function is also a major advantage of this instrument.

\section{GENERAI DESCRIPTION}

The Digital Multifunction Power Measuring System is designed as a precision power system measurement device which measures AC Voltages in two ranges; AC Amperes in six ranges; Watts in twelve ranges; VARs in twelve ranges; Phase Angle in all twelve possible range combinations; and DC Volts in three ranges isolated from the AC circuitry to avoid interaction within the instrument. The instmument is designed as a series of subsystems which act as separate metering circuits, that is, there is an Amps circuit board, a Volts board, a Phase Angle board, et cetera, each of which converts the quantity into a DC voltage which is then monitored and displayed by a \pm 0.02 percent accurate digital panel meter. We used commercially available true RMS and Multiplier modules, but found we had to filter their outputs to achieve their specified accuracy. A block diagram of the entire Digital Multifunction Power Measuring System is shown following as Figure 4. 


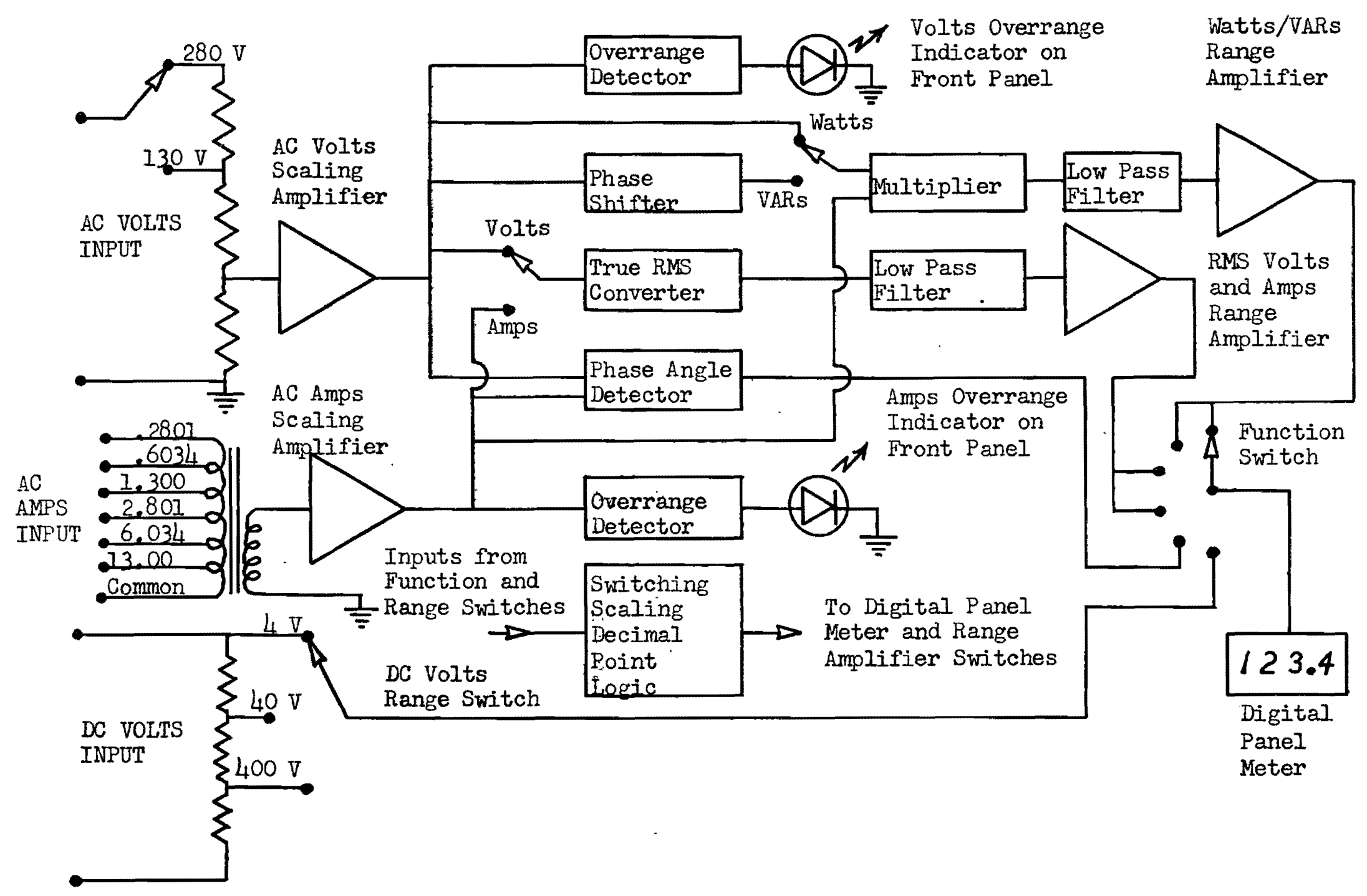

Figure 4. System Block Diagram 


\section{DETAILED DESCRIPTION}

The following detailed description of the Digital Multifunction

Power Measuring System will be broken down much as the system itself is, that is the system as a whole and each of its subsystems. Individual block diagrams of each subsystem are shown, including a logic diagram of the Decimal Point and Switching Logic, but specific circuit schematic diagrams are not shown due to the general descriptive nature of this thesis.

\section{TABLE I}

QUANTITIES MEASURED, RANGES AND ACCURACIES

\begin{tabular}{|c|c|c|c|}
\hline Electrical Par & Full Scale Range & Resolution & Accuracy \\
\hline RMS AC Volts & $\begin{array}{l}130.0 \text { Volts } \\
280.0 \text { Volts }\end{array}$ & $\begin{array}{l}0.1 \text { Volts } \\
0.1 \text { Volts } \\
\end{array}$ & $\begin{array}{l} \pm 1 \text { digit } \\
\pm 1 \text { digit } \\
\end{array}$ \\
\hline RMS AC Amperes & 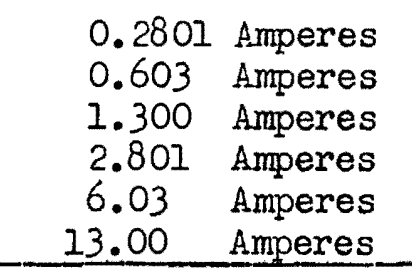 & $\begin{array}{l}100 \text { Microamps } \\
1.0 \text { Milliamps } \\
1.0 \text { Milliamps } \\
1.0 \text { Milliamps } \\
10.0 \mathrm{Milliamps} \\
10.0 \mathrm{Milliamps} \\
\end{array}$ & $\begin{array}{l} \pm 1 \text { digit } \\
\pm 1 \text { digit } \\
\pm 1 \text { digit } \\
\pm 1 \text { digit } \\
\pm 1 \text { digit } \\
\pm 1 \text { digit }\end{array}$ \\
\hline Phase Angle & All AC Ranges & 0.1 Degree & 士0.1 degree \\
\hline VARs, Watts & $\begin{aligned} & 36.41 \text { Watts/VARs } \\
& 78.4 \text { Watts/VARs } \\
& 169.0 \text { Watts/VARs } \\
& 364.1 \text { Watts/VARs } \\
& 784 \text { Watts/NARs } \\
& 1690 \text { Watts/NARs } \\
& 3641 \text { Watts/VARs } \\
&\end{aligned}$ & $\begin{array}{ll}0.01 & V * A \\
0.1 & V * A \\
0.1 & V * A \\
0.1 & V * A \\
1 & V * A \\
1 & V * A \\
1 & V * A \\
\end{array}$ & $\begin{array}{l} \pm 0.1 \% \mathrm{~F} . \mathrm{S} . \\
\pm 1 \mathrm{digit} \\
\pm 0.1 \% \mathrm{~F} . \mathrm{S} . \\
\pm 0.1 \% \mathrm{~F} . \mathrm{S} . \\
\pm 1 \mathrm{digit} \\
\pm 0.1 \% \mathrm{~F} . \mathrm{S} . \\
\pm 0.1 \% \mathrm{~F} . \mathrm{S} .\end{array}$ \\
\hline DC Volts & $\begin{array}{r}4.000 \text { Volts } \\
40.00 \text { Volts } \\
400.0 \text { Volts }\end{array}$ & $\begin{array}{r}1 \text { Millivolt } \\
10 \text { Millivolts } \\
100 \text { Millivolts }\end{array}$ & $\begin{array}{l} \pm 0.03 \% \text { F. S. } \\
\pm 0.03 \% \text { F. S. } \\
\pm 0.03 \% \text { F. S. }\end{array}$ \\
\hline
\end{tabular}


The preceeding table may offer some confusion as to the way the ranges were chosen, and why we chose the strange full scale values of the parameters. There are three basic factors governing the full scale ranges of the instrument:

1. Standard power company voltages of 120 and 240 Volts $A C$ had to be accomnodated.

2. A multiplication is performed to calculate Watts and VARs; this complicated the full scale ranges.

3. To display Phase Angle, a full scale value of 360.0 must be displayed, and to do this on a four and one-half digit (19,999 count) digital panel meter would have forced us down range on the meter for most other parameters degrading overall accuracy.

For these reasons, as well as the availability of a high quality 4000 count digital panel meter, a range multiple equal to the cube root of ten was chosen. To expand on this statement, this value (2.1544) multiplied times any lower range gives the next higher range value for Volts and Amps.

For example: $130.0 \mathrm{~V} * 2.1544=280.1$ Volts

Also: $\quad 0.2801 \mathrm{~A} * 2.1544=0.6034$ Amps Another factor involved in choosing the cube root of ten as the range factor rather than, say, the square root of ten was that it let the WattVAR ranges be further up scale with respect to the range of the digital panel meter. This also enhances the potential accuracy of the instrument since the digital panel meter's accuracy is based strictly on full scale input, and is seriously degraded below one-tenth of full scale. Also, in any digital instrument, there is what is called "least count error". This refers to the $\pm_{1}$ count uncertainty of the least significant digit and is of considerable importance in an instrument appraaching one-tenth of one percent accuracy. 


\section{The Mathematics of the Measurements}

In the original Watt Transducer, we built our own pulse heightwidth modulator which performed the necessary multiplication to obtain Watts. When we embarked on the later project of the Digital Multifunction Power Measurement System, modules which performed this function and True RMS function had become commercially available. Due to the economics of the job, we chose to use two Intronics modules in the instrument. However, for clarity, the mathematics involved in sinusoidal multiplication are included here:

Width of pulses controlling Height Modulator Switch $=A+V$ sin wt Height of pulses at output of Modulator Switch $=I \sin$. $($ wt $+\emptyset)$ Area of each pulse at output of Modulator Switch:

$$
\begin{aligned}
\text { AREA } & =[A+V \sin w t] *[I \sin (w t+\phi)] \\
& =A I \sin (w t+\phi)+V I \sin w t \sin (w t+\phi) \\
& =A I \sin (w t+\phi)+V I \sin w t *[\sin w t \cos \phi+\cos w t \sin \phi] \\
& =A I \sin (w t+\phi)+V I \sin ^{2} w t \cos \phi+V I \sin w t \cos w t \sin \varnothing
\end{aligned}
$$

On the average over one period: AI $\sin (w t+\emptyset)=0$

Using (wt) as reference (zero): VI $\sin w t=0$

Therefore, the average $D C$ value of the Area equation is:

$D C$ Value of Area $=V I \cos \varnothing$

Definition of Watts : VI $\cos \varnothing$

Where $\emptyset=$ Angle between $V$ and $I$

\section{Operational Description}

As $\emptyset$ goes to zero degrees, $\cos \varnothing$ goes to unity giving a pure $V * I$ product. As $\varnothing$ goes to ninety degrees, $\cos \varnothing$ goes to zero giving zero Watts or pure reactive power. As $\emptyset$ goes from ninety degrees to one hundred 
eighty degrees, $\cos \emptyset$ goes from zero to minus one giving a pure negative $\mathrm{V} *$ I product. This repeats from one hundred eighty degrees around to three hundred sixty degrees. The useful range is from minus ninety degrees to plus ninety degrees which covers unity power factor through all negative and positive power factors up to and including zero, that is all leading and lagging power factors.

The VARs portion of the instrument works in exactly the same manner as the Watts portion, except that we have inserted a phase shifter into the AC Volts circuit. The shifted AC volts signal lags its input by exactly ninety degrees which makes the VARs positive when the Amps signal is in the first or second quadrant (zero to one hundred eighty degreés). This is consistent with the definition of reactive power, VARs, that is:

$$
V A R s=V * I \sin \varnothing
$$

Since we have show our multiplier to result in,

$$
\begin{aligned}
& \text { Watts }=V * I \cos \varnothing \\
& \text { and } \sin \varnothing=\cos (90-\varnothing)
\end{aligned}
$$

Therefore, $\mathrm{VARs}=\mathrm{V} * \mathrm{I} \cos (90-\varnothing)$

This is how the VARs portion of the instrument works, and it is completely consistent wi.th the definition of VARs, that is Volt-Amperes Reactive or Reactive Power. 
True RMS Conversion

The effective value of a periodic wave form is equal to the value of the direct current which, when flowing through a given resistance, delivers the same power to the resistance as the periodic current. Mathematically, this is defined as follows and called the Root Mean Square or RMS value of the periodic current.

$$
\begin{aligned}
& \text { Irms }=I \text { effective }=\sqrt{1 / \tau \int_{0}^{T} i^{2} d \tau} \\
& \text { Erms }=\text { E effective }=\sqrt{1 / \tau \int_{0}^{T} e^{2} d \tau}
\end{aligned}
$$

These two equations hold for all periodic currents and voltages no matter what their frequency or harmonic content. Unfortunately, the nature of the equations, an integral, a square, and a root, makes them hard to measure in practive. We also used an Intronics module to make this measurement, and it converts the $A C$ waveform into a DC voltage which we filter and measure with the digital panel meter. 


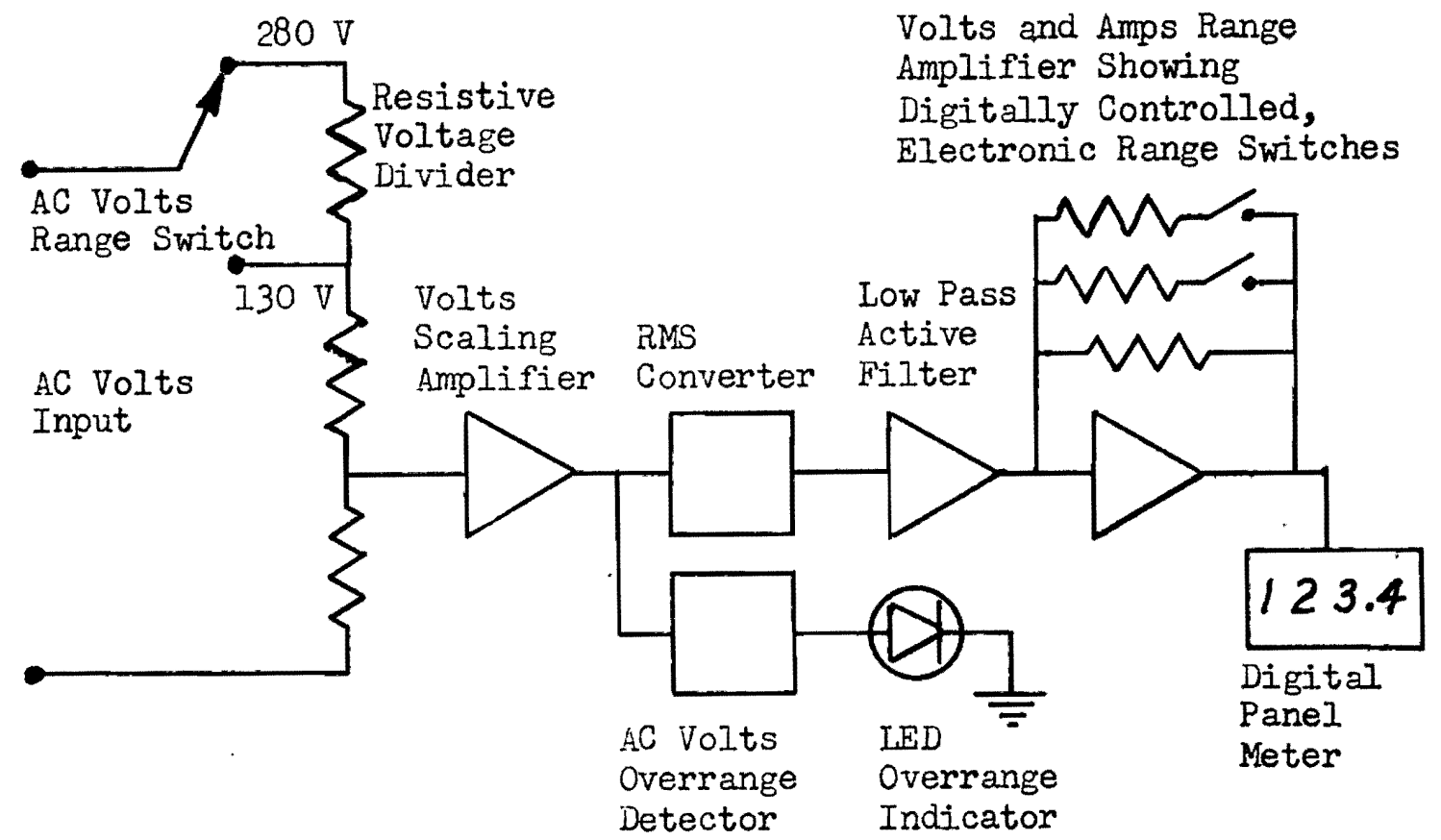

Figure 5. AC Volts Circuit Block Diagram

Description of Operation

An input voltage is divided down to 5.66 volts peak-to-peak maximum, scaled up to 20.00 volts peak-to-peak maximum at the imput of the RMS converter. The RMS module converts it to $D C$ of the proper magnitude $(7.071$ Volts maximum); this $D C$ is then filtered to remove the pulse width modulation frequency. The filtered DC voltage is then attenuated by the AC Volts and Amps range amplifier to the proper level and fed to the Digital Panel Meter where this voltage is displayed. The proper gain of the V-A range amplifier is determined by the position of the Volts Range Switch which also determines the Digital Panel Meter decimal point location. This all has to coincide with the position of the Function Switch which has logical override over the other switches. 


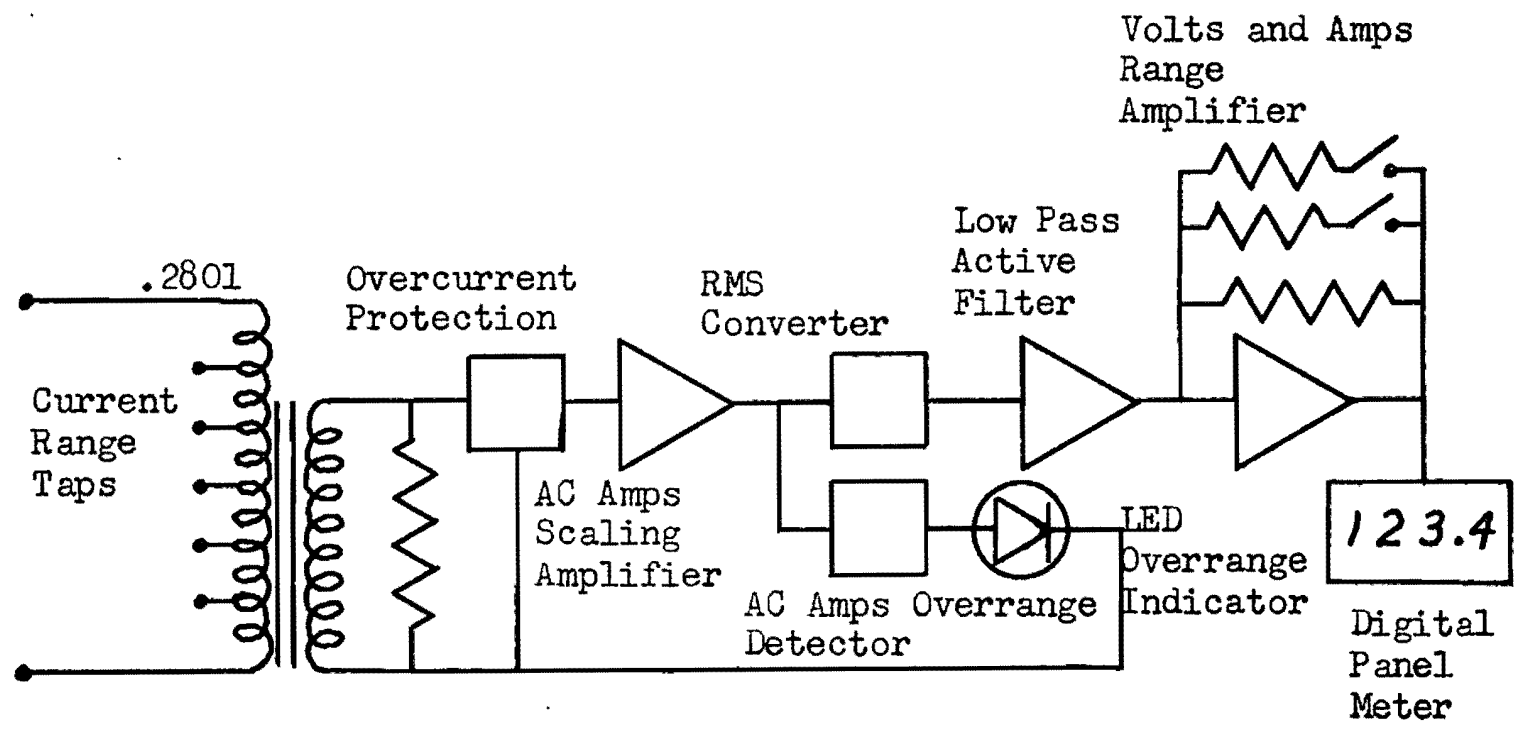

Figure 6. AC Amps Circuit Block Diagram

Description of Operation

An input current is fed into a current transformer which gives an approximate 2.828 Volts peak-to-peak full scale for each current tap. This voltage is then amplified by the Amps Scaling Amplifier which has individually set gain for each tap of the current transformer by means of the Current Range Switch. This output is sampled by the Overrange Detector to make sure it doesn't exceed the limits of the instrument. As the output of the Amps Scaling Amplifier goes into the RMS module, it follows the same path as the AC Volts signal. It is transformed into a DC voltage by the RMS module; is filtered by the Low Pass Active filter; is attenuated to give the proper output voltage to the Panel Meter by the Volts and Amps Range Amplifier; and finally is displayed on the Digital Panel Meter as a DC voltage equivalent to the RMS value of the Amps input through the Current Transformer. 
Watts and VARs Circuit

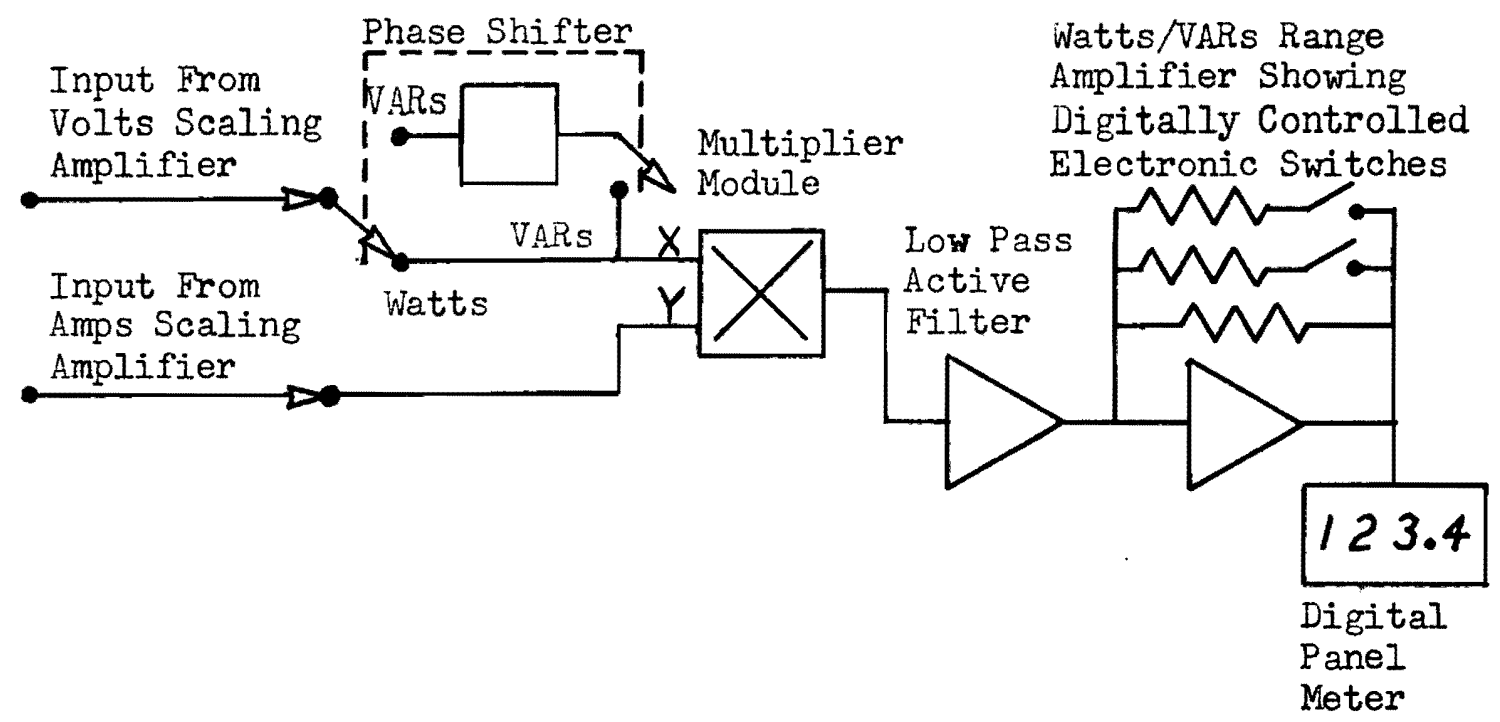

Figure 7. Watts/VARs Circuit Block Diagram

Description of Operation

The circuitry up to the multiplier is the same as in the Volts and Amps input circuitry. As explained previously, we have placed a switchable series phase shifter (90.0 degrees) in the Volts circuit for the VARs circuit. Both Volts and Amps signals are fed into the Multiplier Module which puts out a $D C$ voltage equivalent to $[(X * Y) / 10] \cos \emptyset$ where $\varnothing$ is the phase angle between the Volts and Amps signals as described in the Mathematics of the Measurements section. This output is then filtered by the Low Pass Filter to remove the pulse width modulation frequency and presented to the Watt/VAR Range Amplifier. This amplifier scales the DC voltage proportional to Watts or VARs to the corresponding level chosen by the Volts and Amps Range Switches. This scaling is done by changing the feedback by means of logic controlled electronic switches within the amplifier's feedback path. This is essentially the same system as used in the Volts and Amps Range Amplifiers except that two variables are 
involved instead of only one. The output is then displayed on the Digital Panel Meter as Watts or VARs. 
Phase Angle Circuit

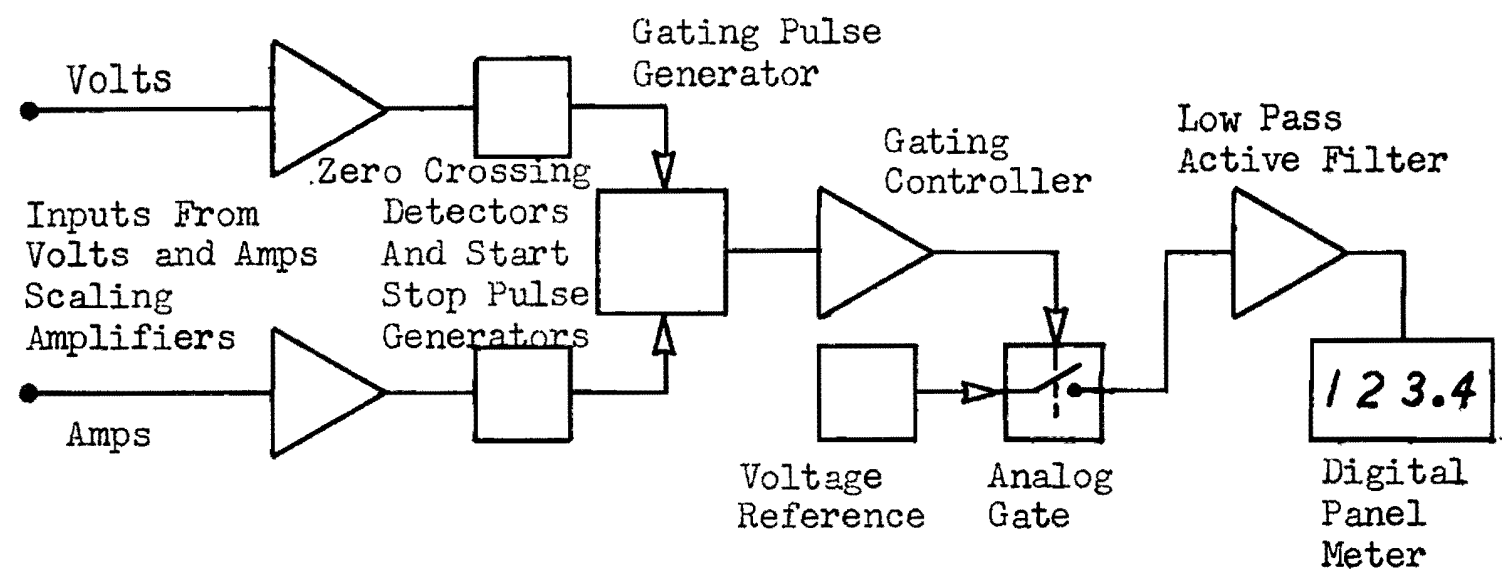

Figure 8. Phase Angle Circuit Block Diagram

Description of Operation

The outputs from the Volts and Amps Scaling Amplifiers are fed through the Function Switch to the 60 Hertz Bandpass Filters. These are unity gain, non-inverting filters tuned to pass sixty plus or minus two Hertz signals with no attenuation or phase shift. The outputs of these filters are then fed into identical inverting Zero Crossing Detectors which switch state within two micro-seconds of the filtered input sine wave crossing the zero Dolts axis. The square waves generated by the Zero Crossing Detectors are then differentiated by the Start/Stop Pulse Cenerators which generate a one micro-second negative going pulse for each positive transition of the square wave. These pulses, which represent the phase angle between Volts and Amps inputs in terms of time difference per cycle, control the Gating Pulse Generator. The periodic rectangular wave output of the Gating Pulse Generator provides timing for the Gating Controller which drives the analog gate through which the 3.600 Volts Reference Voltage passes. This gated Reference Voltage is then 
buffered and filtered by the Low Pass Active Filter which puts out a time averaged DC voltage precisely proportional to the Phase Angle between the Volts and Amps input signals. This DC voltage is then measured and displayed on the Digital Panel Meter whose decimal point is positioned by the Function Switch through the Decimal Point Control Logic. 
DC Volts Circuit

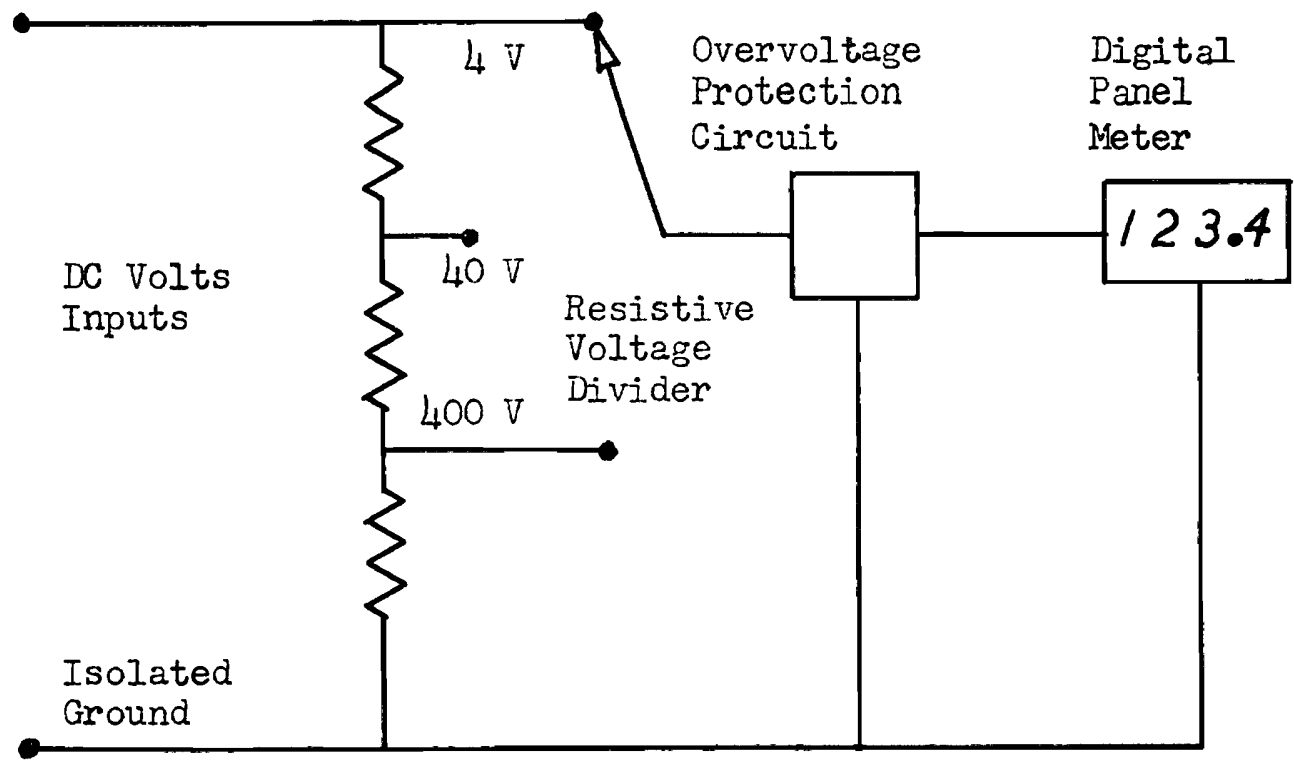

Figure 9. DC Volts Circuit Block Diagram

\section{Description of Operation}

Through separate inputs, completely isolated from those of the other circuits, a DC voltage is fed through an over-voltage Protection Circuit and the Function Switch to the Digital Panel Meter. In the DC Volts function, the Digital Panel Meter inputs are switched uniquely to the DC Volts input terminals (both high input and ground) to prevent any feedthrough of signal from the other circuits or ground loop effects. The decimal point position is selected by the position of the Function and DC Volts Range Switches, and located by the Decimal Point Control Logic. Within the Digital Panel Meter, the control logic is isolated from the inputs so that extremely high common mode rejection is achieved as well as normal mode rejection of the AC circuitry within the Digital Multifunction Plower Measuring System. 
Description of Operation, Logic Circuit

The Switching, Scaling, and Decimal Point Logic is comosed of fifty transistor-transistor logic gates contained in thirteen integrated circuits which control the decimal point location on the Digital Panel Meter, the gain of AC Volts and Amps Range Amplifier, and the gain of the Watt/VAR Range Amplifier. The logic circuits receive their information from the positions of the Function and Range Switches, decode this information, and then drive transistors for decimal point location or drive electronic switches to change the gain of the Range Amplifiers. The best way to describe these functions is to show the logic equations based on the following table of input range and function possibilities.

\section{TABEE II}

LOGIC DESIGNATION OF FUNCTIONS AND RANGES

\begin{tabular}{lcc} 
Function & Ranges & Designation \\
\hline \multirow{2}{*}{ AC Volts } & 130 & $\mathrm{~B}$ \\
& 280 & $\mathrm{C}$ \\
\hline \multirow{2}{*}{ AC Amps } & .2801 & $\mathrm{D}$ \\
& .6034 & $\mathrm{E}$ \\
& 1.300 & $\mathrm{~F}$ \\
& 2.801 & $\mathrm{~K}$ \\
& 6.034 & $\mathrm{~L}$ \\
& 13.00 & $\mathrm{M}$ \\
\hline \multirow{2}{*}{ DC Volts } & 4.000 & 2 \\
& 40.00 & 3 \\
& 400.0 & 4 \\
\hline \multirow{2}{*}{ Function } & Watts NARs & 5 \\
Switch & AC Volts & 6 \\
& AC Arms & 7 \\
& Phase Angle & 8 \\
& DC Volts & 9
\end{tabular}


Mathematics of the Logic Circuit

The following are the defining equations for the logic conditions covering switching, feedback, and locating the decimal point:

Switch 1, 6034 output, Volts and Amps Range Amp. $=7 \cdot\left(E_{+} I\right)$

Switch 2, 1300 output, Volts and Amps Range Amp. $=7 \cdot(F+M)+(B \cdot 6)$

Switch 3, 784 output, Watts/VARs Range Amp. $=(5 \cdot B) \cdot(E+I)+(5 \cdot C) \cdot(+K)$

Switch 4, 1690 output, Watts/NARs Range Amp. $=(5 \cdot B) \cdot(F+M)+(5 \cdot C) \cdot(E+L)$

No Decimal Point (DP-0)

$D P-0=(B \cdot 5) \cdot(L+M)+(C \cdot 5) \cdot(K+L)+(C \cdot M \cdot 5)$

Decimal Point one position from right (DP-1)

$D P-I=6 \cdot(B+C)+8+(4 \cdot 9)+(C \cdot 5) \cdot(D+E+F)+(B+5) \cdot(E+F+K)$

Decimal Point two positions from right (DP-2)

$D P-2=7 \cdot(M+2)+(3 \cdot 9)+(B \cdot D \cdot 5)$

Decimal Point three positions from right (DP-3)

$\mathrm{DP}-3=7 \cdot(\mathrm{E}+\mathrm{F}+\mathrm{K})+(2 \cdot 9)$

Decimal Point four positions from right (DP-4)

$D P-4=(D \cdot 7)$

These reduced equations describe all possible Range and Function switch combinations. The Logic Diagrams which these equations describe are shown following as Figures 10 and 11 . 


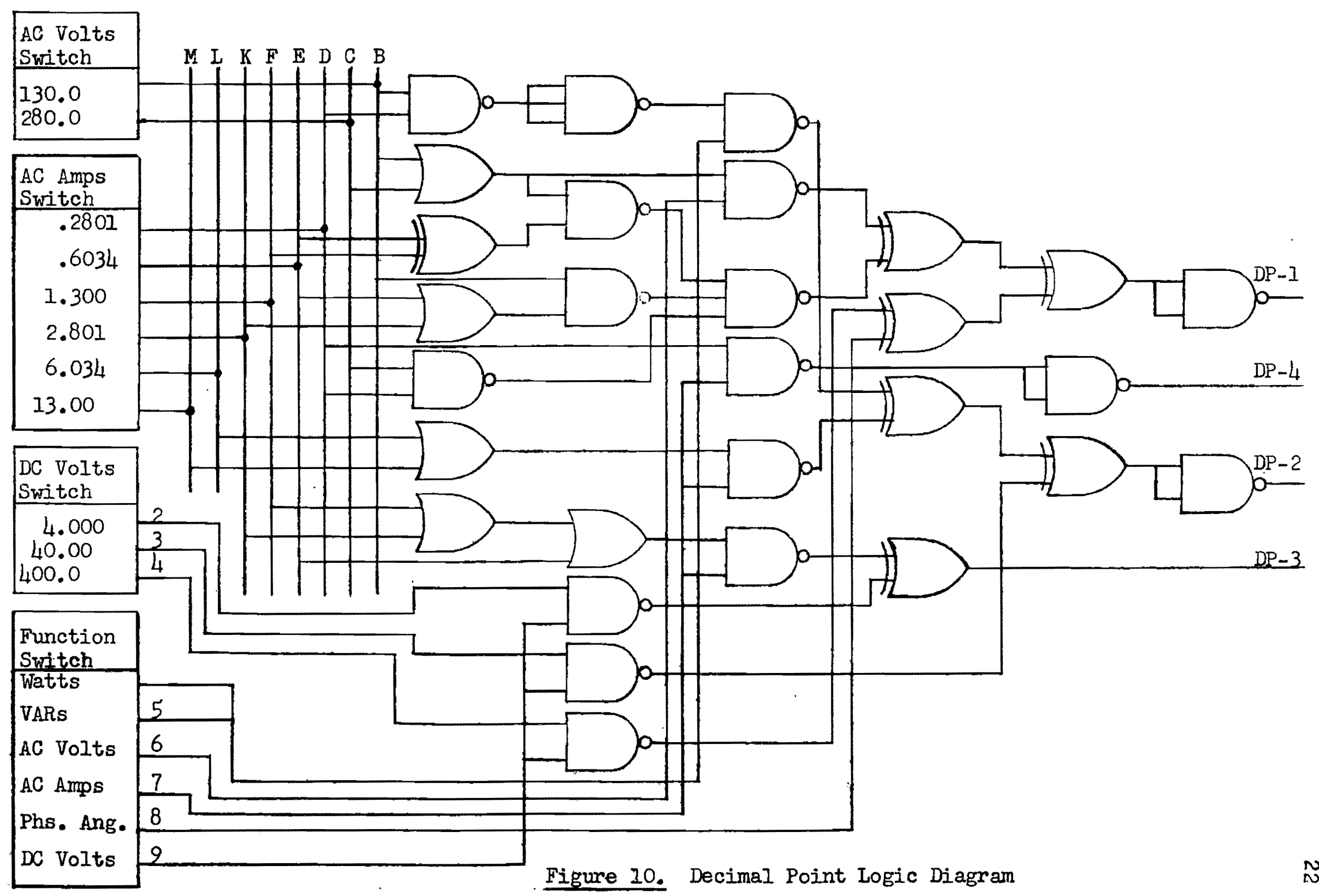




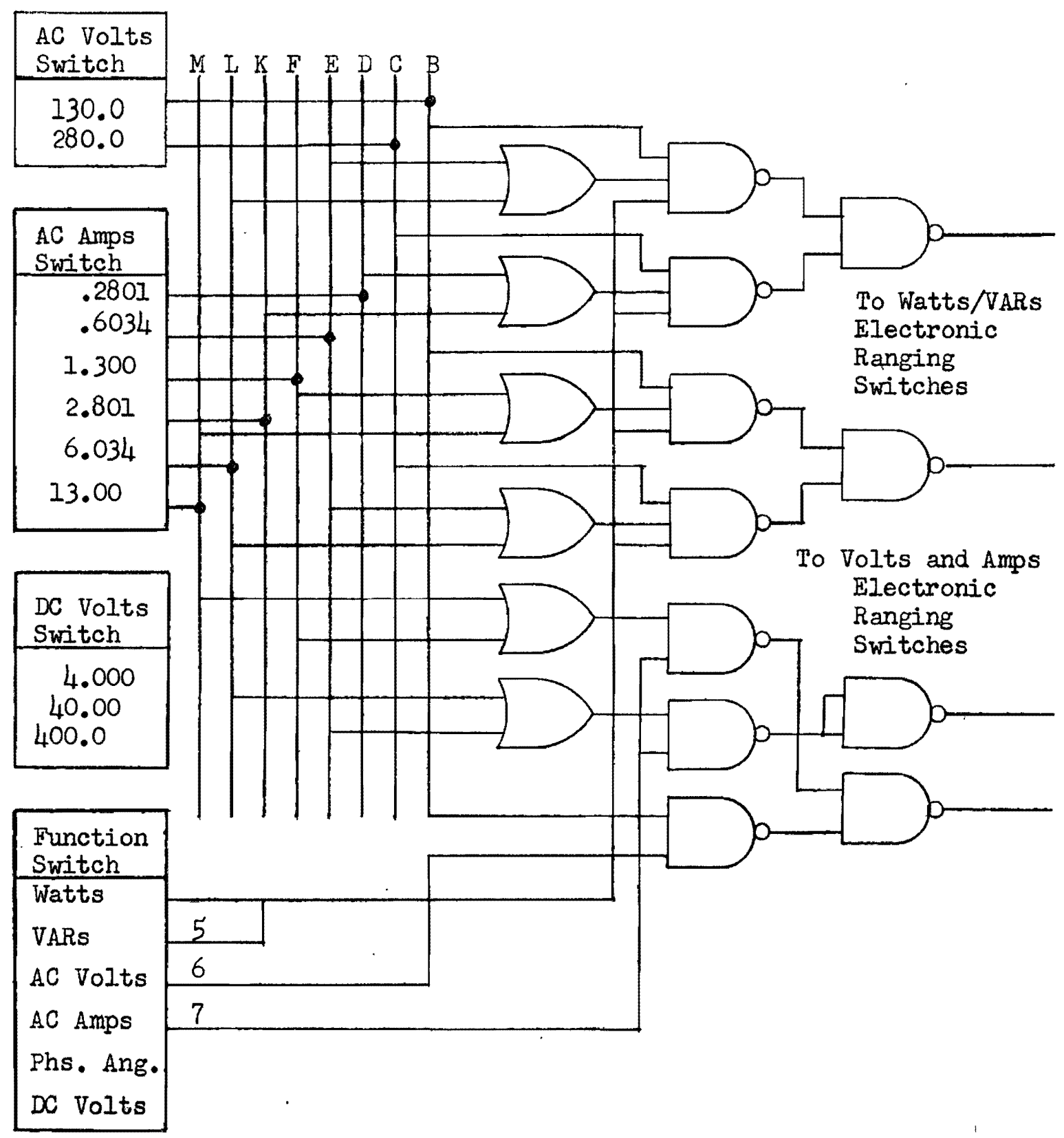

Figure 1l. Switching and Scaling Logic Diagram 
Construction

The Logic portion of the Digital Multifunction Power Measuring: System is composed entirely of the Transistor Transistor Logic family of integrated circuits with the exception of the four high voltage transistors used to drive the Nixie (R) tube decimal points in the Digital Panel Meter. All the Logic and the four transistors are contained on one four-and-one-half by six inch circuit board which was hand wired using solder joints for positive connections. Since this was a one-ofa-kind instrument, we could not economically make printed circuit boards for mounting the components. The wiring was done in such a fashion to lend itself easily to conversion to printed circuits if the need arose for more of these to be built.

Other than overload protection diodes, Light Emitting Diodes (IEDs), voltage reference and/or clipping diodes, and a single Field Effect Transistor (FET), the entire Scaling, Range, and Phase Angle circuits are composed of linear integrated circuits or Analog Modules. Precision metal film resistors, polystyrene and Mylar (R) capacitors, and wire-wound trim potentiometers with low temperature coefficient of resistivity were used in all critical areas. All circuits are fused or otherwise protected to prevent damage to components in the case of over-voltage or current as well as transients presented to the System's inputs. Coaxial cable was used for all signal carrying connections between circuit boards and/or switches due to the presence of strong electro-magnetic fields without and within the instrument. The instrument utilizes two highly regulated DC power supplies with better than 0.01 percent line and load regulation and 0.1 percent temperature stability. This was a basic design criterion due to the desired 
accuracy of the instrument, the varying ambient temperatures in which it might be used, and the need for stable reference voltages within the instrument. Passive decoupling was used on all circuit boards to minimize stray pickup in the power supply busses and deregulation caused by load and/or distance differences between boards. Common, easily obtainable components were used throughout the instrument to minimize costs, and other than the two Analog Modules, all the individual circuits were designed and teșted in-house. Physical and electrical shielding was used to minimize electromagnetic and thermal transfer within the commercially available instrument case within which we installed our circuit boards, Digital Panel Meter, and switches.

Mach of the actual circuit design is the result of Computer Aided Design using computer programs developed by the author. This useful technique saved countless hours which would have been required for the hand derivation and calculation of the various filters, amplifiers, and phase shifter design equations. The Logic Circuit minimization was done by hand due to the lack of useful computer programs in this area, and the inability of our computer to handle string variables necessary for QuineMcCluskey minimization techniques. Karnough maps were not used due to the number of variables present in the logic equations.

Following, as labeled, are photographs of the individual circuit boards used in the instrument, and a top view photograph of how they fit inside the instrument case. As mentioned previously, we anticipate the need for several of these instruments within the BPA system, and all construction used readily available parts to enable easy reproduction of the instrument on a commercial basis. As in any prototype development 
there would be some engineering changes prior to production, but we feel we have anticipated most of those necessary to make the transition from prototype to production relatively simple.

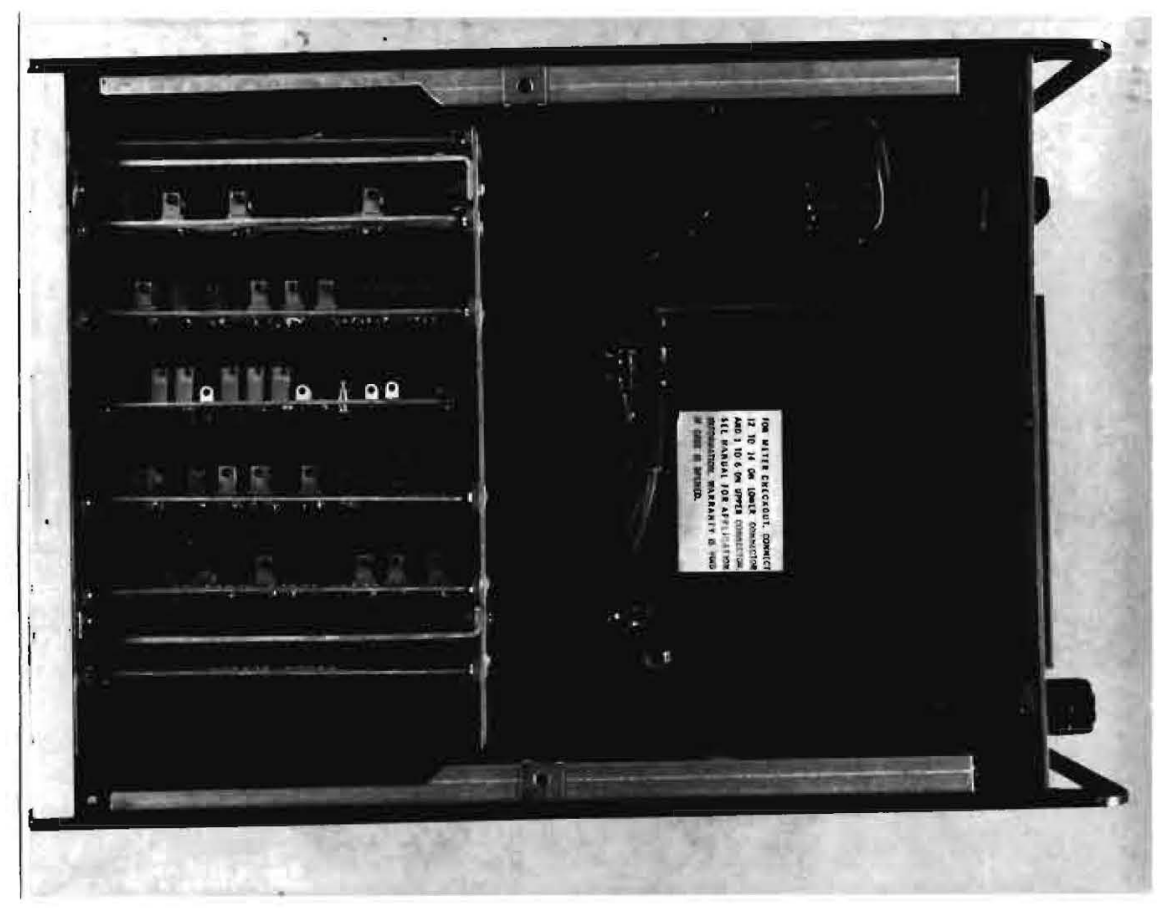

Figure 12. Top View of Instrument Showing Location of Circuit Boards, Switch, and Digital Panel Meter. 


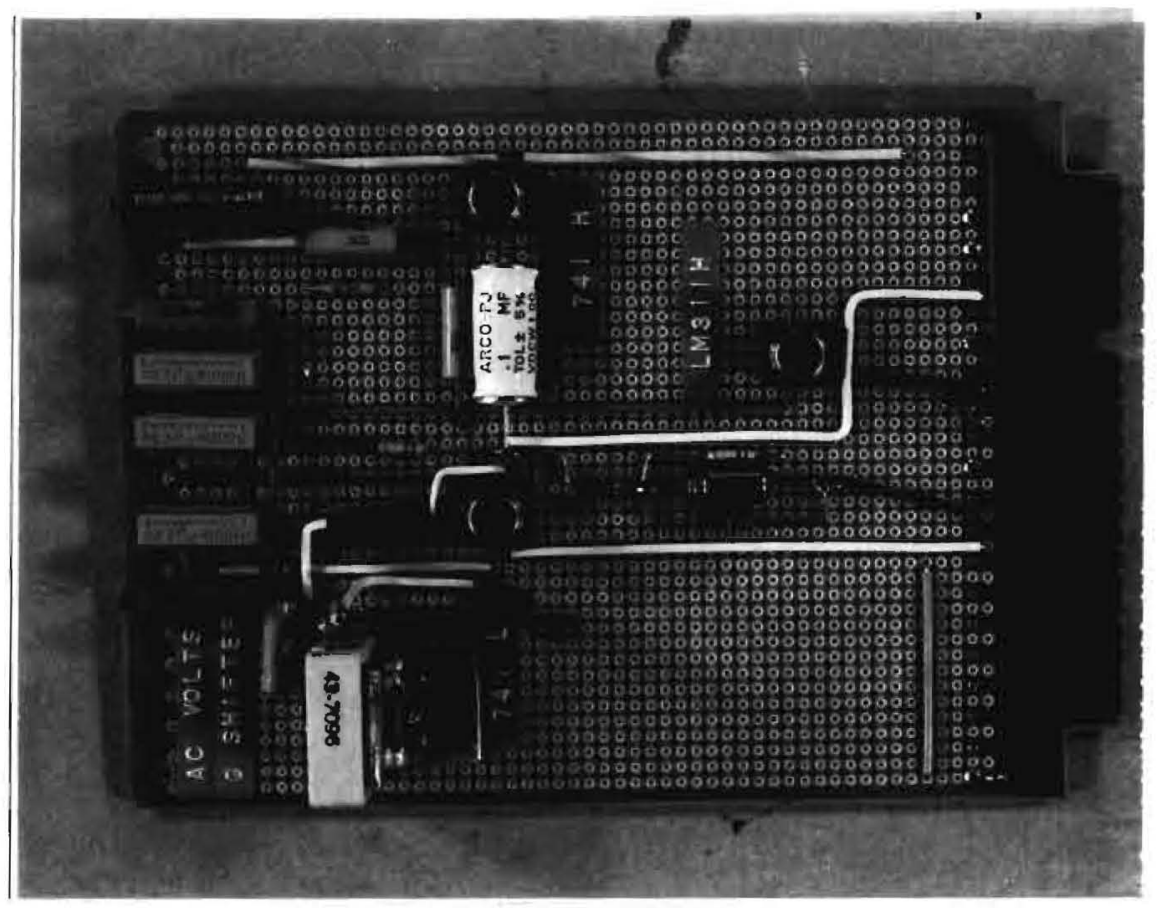

Figure 13. AC Volts and Phase Shifter Circuit Board

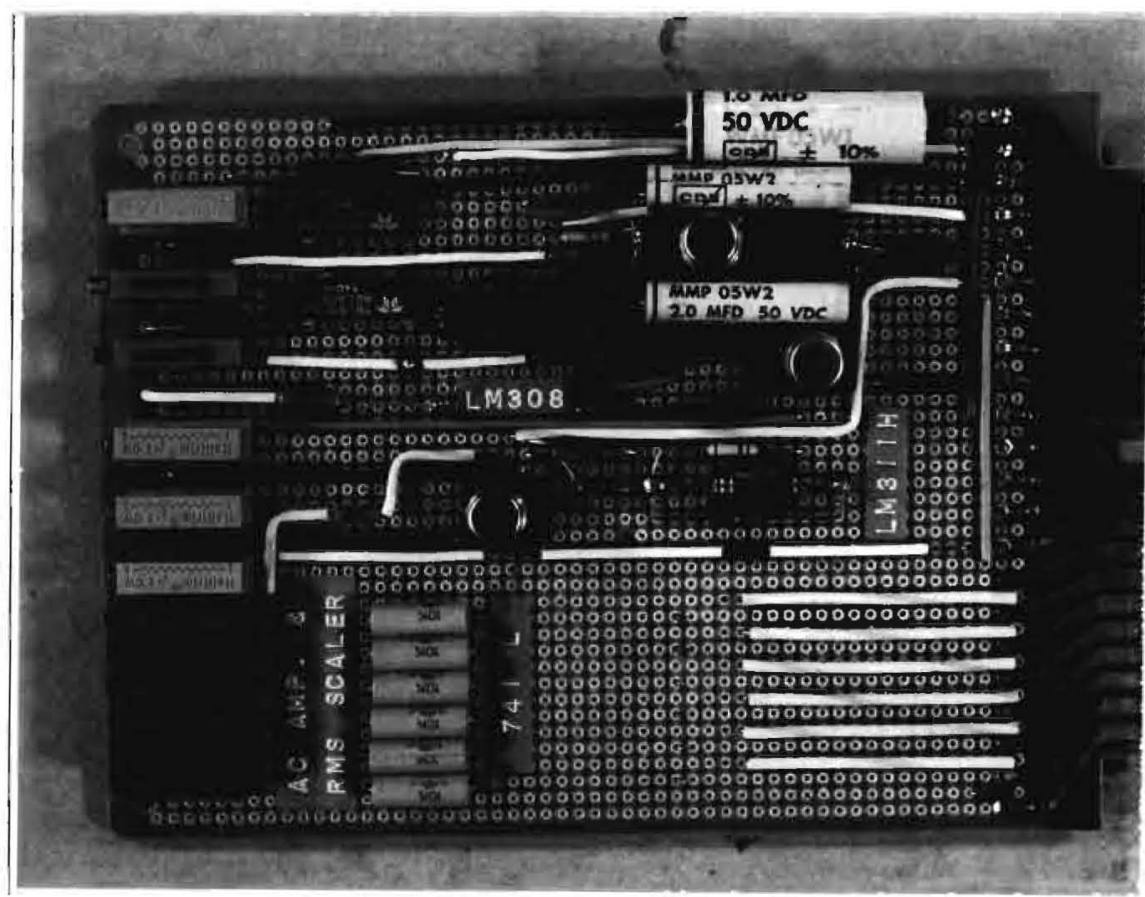

Figure 14. AC Amps and RMS Scaler Circuit Board 


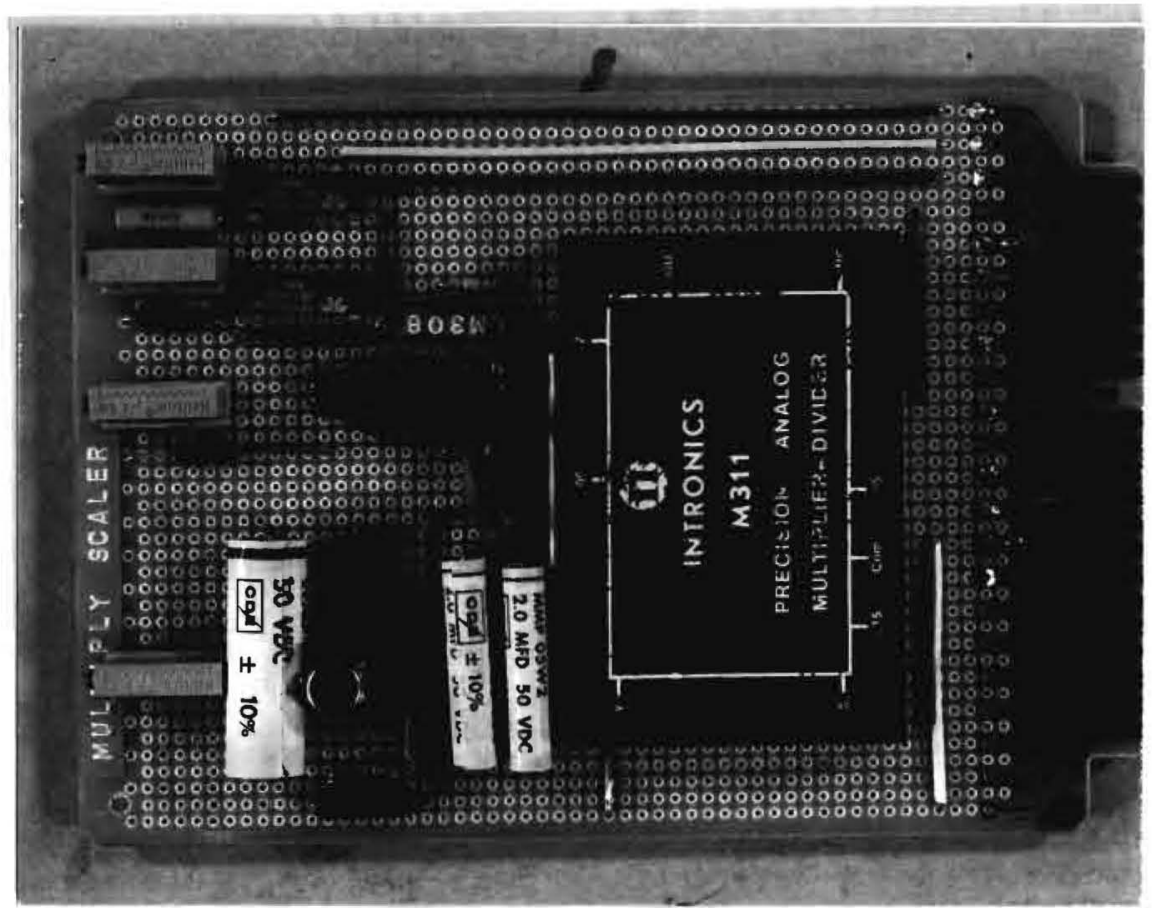

Figure 15. Multiplier Module and Watts/VARs Range Amplifier Circuit Board

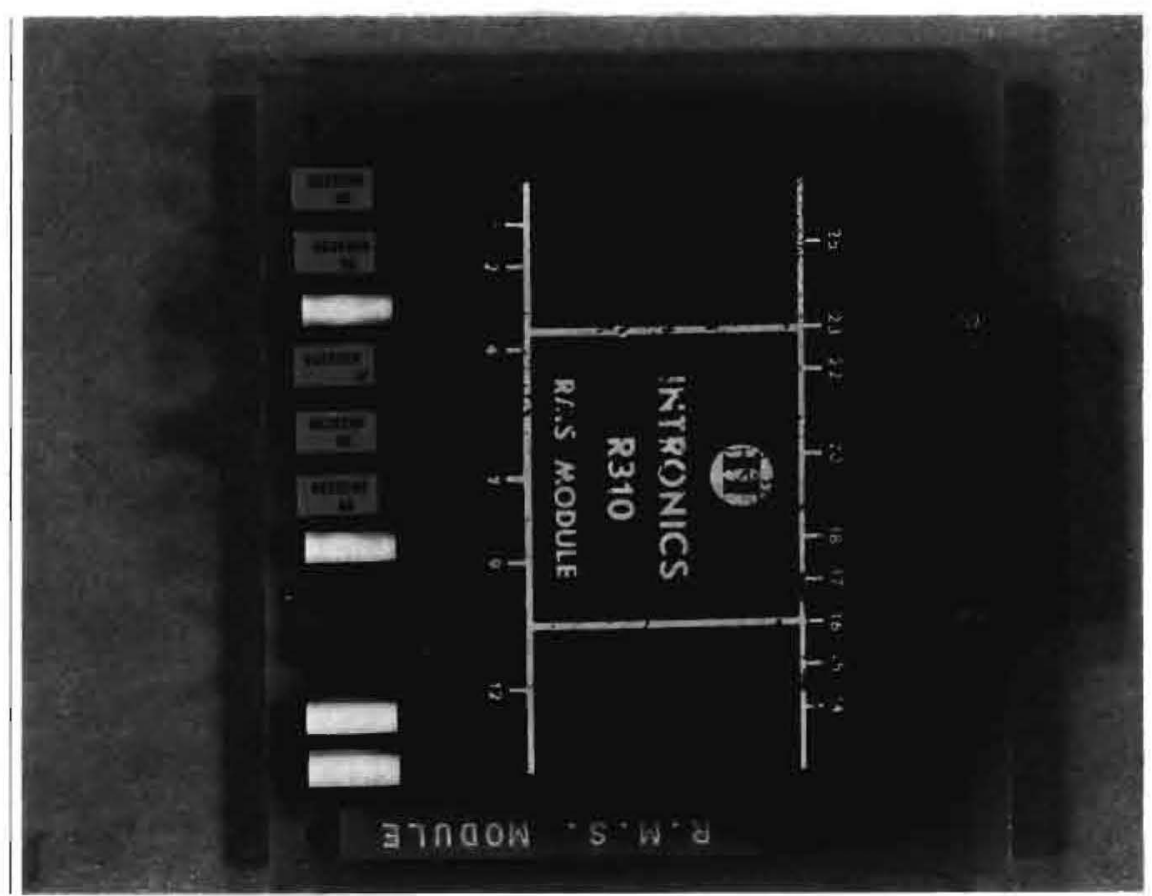

Figure 16. RMS Module Circuit Board 


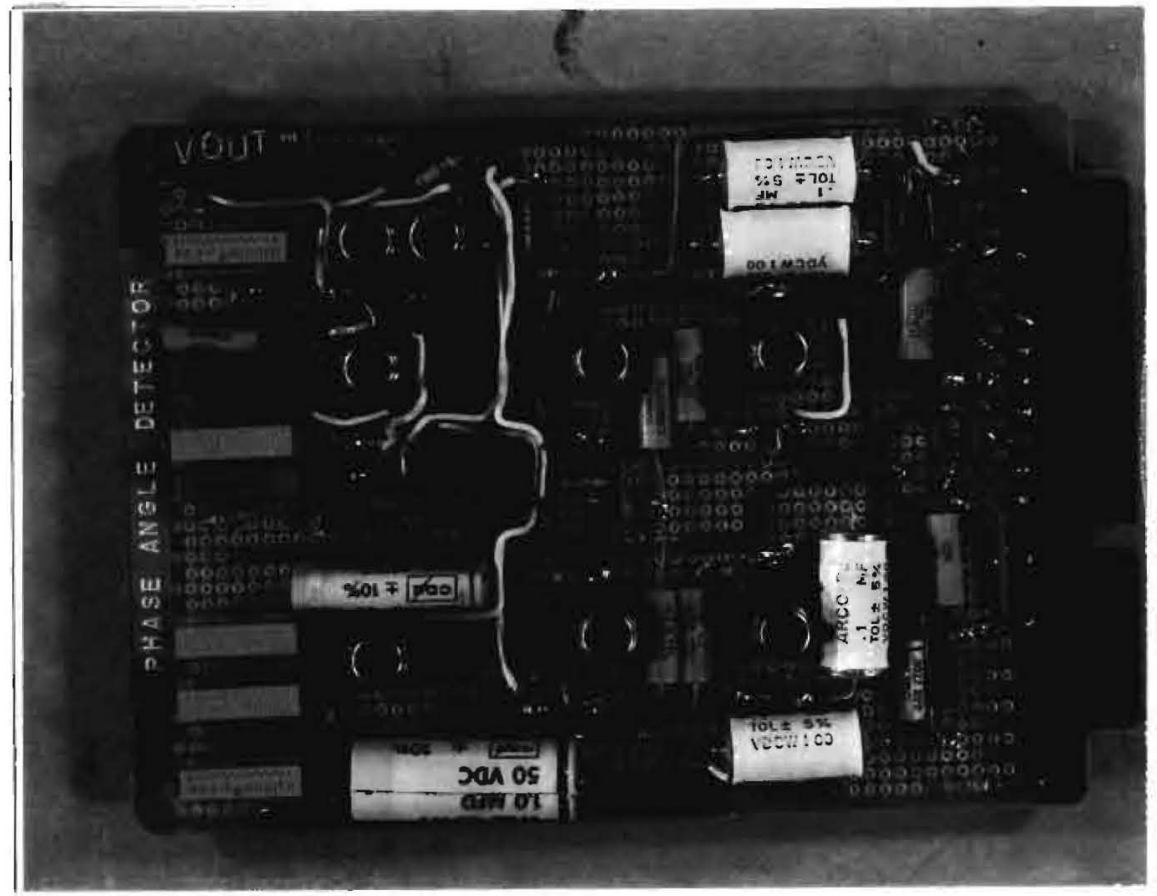

Figure 17. Phase Angle Circuit Board

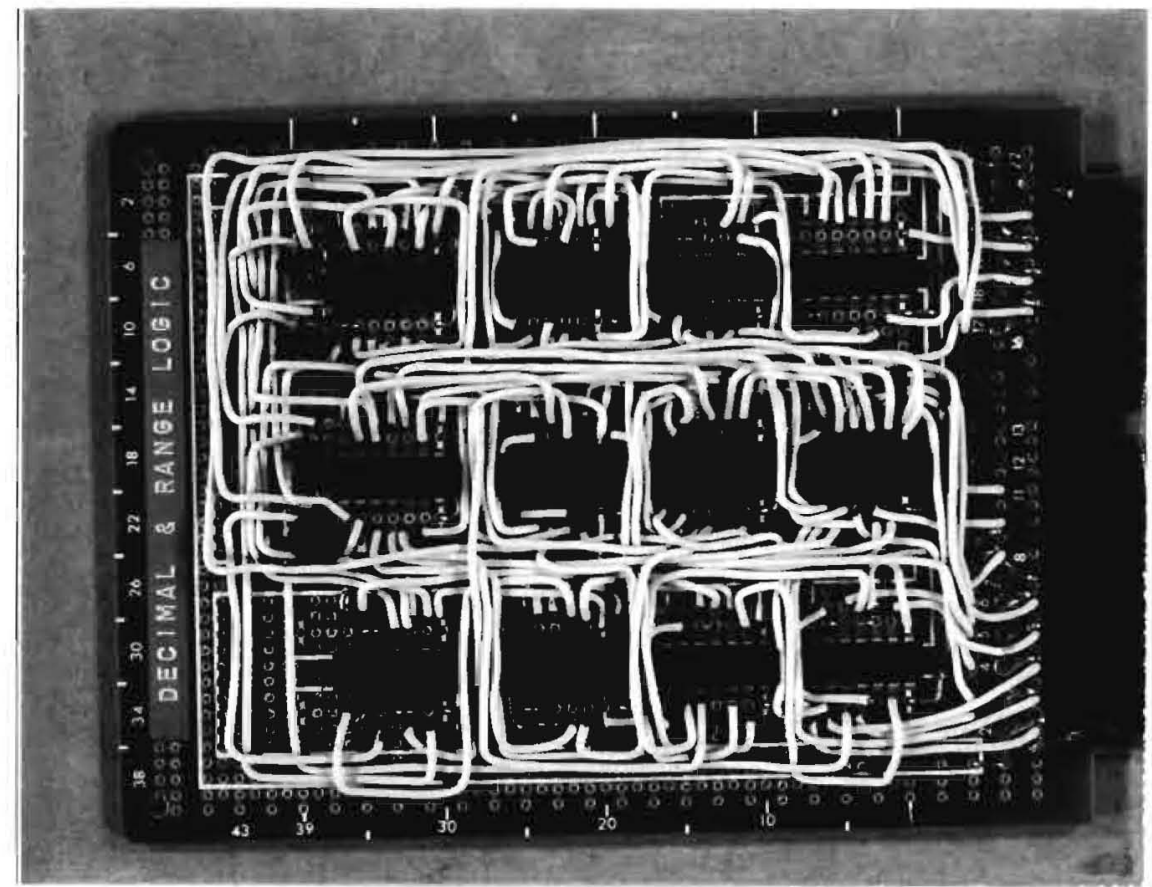

Eigure 18. Switching, Scaling, and Decimal Point Logic Circuit Board 
SUIMNARY

It has been attempted to show the background of, the need for, and the design considerations of the Digital Multifunction Power Measuring System. This instrument has been physically and electrically tested by the Low Frequency Standards Unit of the Instrumentation and Standards Laboratory of the Bonneville Power Administration, and been show to meet or exceed all its design specifications.

This instrument has been demonstrated to other Units within BPA and has been sent to some Area Offices to test its applicability to field use with the BPA System. After field test and demonstration, its intended use will be as the Calibration Standard for Watt and Watt-Hour transducers in the Instrument Service Unit of the Instrumentation and Standards Laboratory at the J. D. Ross Substation Complex in Vancouver, Washington.

It is the hope of the author that this instrument will become the prototype of many instruments to follow which will become cost-effective tools to aid in field measurement of power parameters, and will result in increased accuracy of measurement and man-hours saved on the Bonneville Power Administration Power Distribution System. 


\section{REFERENCES}

Graeme, J. G. 1973, "Applications of Operational Amplifiers: Third Generation Techniques," McGraw-Hill Book Company, New York.

Grzeme, J. G., Huelsman, I. P., and Tobey, G. E. 1971, "Operational Amplifiers: Design and Applications," Mc-Graw-Hill Book Company, New York.

Motchenbacher, C. D. and Fitchen, F. C. 1973, "Low-Noise Electronic Design," John Wiley and Sons, Inc. 